\title{
Enantiomer discrimination
} in $\beta$-phenylalanine degradation by a newly isolated Paraburkholderia strain BS115 and type strain PsJN

\author{
Oliver Buß ${ }^{*}$, Sarah-Marie Dold, Pascal Obermeier, Dennis Litty, Delphine Muller, Jens Grüninger \\ and Jens Rudat
}

\begin{abstract}
Despite their key role in numerous natural compounds, $\beta$-amino acids have rarely been studied as substrates for microbial degradation. Fermentation of the newly isolated Paraburkholderia strain BS115 and the type strain P. phytofirmans PsJN with $\beta$-phenylalanine ( $\beta$-PA) as sole nitrogen source revealed (S)-selective transamination of $\beta$-PA to the corresponding $\beta$-keto acid by both strains, accompanied by substantial formation of acetophenone (AP) from spontaneous decarboxylation of the emerging $\beta$-keto acid. While the PsJN culture became stationary after entire (S)- $\beta$-PA consumption, BS115 showed further growth at a considerably slower rate, consuming (R)- $\beta$-PA without generation of AP which points to a different degradation mechanism for this enantiomer. This is the first report on degradation of both enantiomers of any $\beta$-amino acid by one single bacterial strain.
\end{abstract}

Keywords: $\beta$-Phenylalanine, $\omega$-Transaminase, Kinetic resolution, Chiral resolution, Paraburkholderia sp., Fermentation, Acetophenone degradation

\section{Introduction}

The catabolism of proteinogenic L-alpha-amino acids $(\mathrm{L}-\alpha-\mathrm{AA})$ is in-depth understood and part of undergraduates' biochemical education (Voet and Voet 2011). In contrast, bacteria have long been known to be a rich source of $D-\alpha$-aa which are therefore abundant in soil and fermented food (Brückner and Hausch 1989). The bacterial synthesis mechanisms of D- $\alpha$-AA and their incorporation in non-ribosomal peptides are now well-understood (reviewed by Radkov and Moe 2014). However, in some cases the enzymes for these reactions are still unknown. Furthermore, not only L- $\alpha$ - and D- $\alpha$-AA are present in nature and reactions towards amino acids with amino groups in other positions than $\alpha$-position are possible, leading to $\beta-, \gamma^{-}, \varepsilon-$ and other constitutional isomers of

\footnotetext{
*Correspondence: oliver.buss@kit.edu; jens.rudat@kit.edu Section II: Technical Biology, Institute of Process Engineering in Life Sciences, Karlsruhe Institute of Technology (KIT), Engler-Bunte-Ring 3, 76131 Karlsruhe, Germany
}

amino acids. $\varepsilon$-amino acids have e.g. a special significance in the biosynthesis pathway of $\beta$-lactams in actinomycetes and are converted by lysine $\varepsilon$-aminotransferases (Duan et al. 2016).

By contrast, only minor insight has been gained into the degradation of $\beta$-amino acids ( $\beta$-AA). With the exception of $\beta$-alanine and $\beta$-aminoisobutyric acid which constitute key intermediates in several metabolic pathways, $\beta$-AA are not as abundant in nature as their $\alpha$-configured counterparts. $\beta$-alanine can be metabolized by mammalia (Nutzenadel and Scriver 1976) and is involved in pantothenate metabolism (Spitzer et al. 1988), finally becoming a component of the key metabolite coenzyme A (CoA). $\beta$-alanine is also linked with histidine by carnosine synthase to the dipeptide carnosine which is abundant in skeletal muscles as well as in the central nervous system of most vertebrates (Drozak et al. 2010). Using the KEGG-pathway tool for analyzing the degradation of $\beta$-alanine, it can be seen that a transaminase reaction is forming 
malonate-semialdehyde which is further converted to malonate and finally enters the fatty acid biosynthesis as malonyl-CoA (Kanehisa et al. 2016).

However, $\beta$-AA have been recognized as essential parts in a variety of biologically active compounds. Beside the incorporation of $\beta$-AA in non-ribosomal peptides and their polyketide hybrids by several bacteria, it has also been shown that plants produce $\beta$-AA containing natural compounds, with the terpenoid- $\beta$-AA hybrid Paclitaxel as the most prominent example (better known as the anticancer therapeutic Taxol) (Wani et al. 1971). In the last two decades, $\beta$-AA also raised interest as building blocks for $\beta$-peptides, which are able to form proteaseresistant, stable and predictable secondary structures and thus promise applications as peptidomimetics (Seebach and Gardiner 2008; Steer et al. 2002). Furthermore, cyclized and substituted $\beta$-AA like $\beta$-lactams constitute the most common antibiotics and also show additional encouraging pharmacological properties; moreover, some free $\beta$-AA show pharmacological effects such as antifungal agent (Ziegelbauer et al. 1998; Magriotis 2001; Juaristi and Soloshonok 2005). In addition, aromatic $\beta$-amino acids might be useful for the creation of artificial flavors like tobacco aroma (Tao et al. 2017). The synthesis of $\beta$-AA and their incorporation into natural compounds has been extensively reviewed by Kudo et al. (2014). Microorganisms appear to be routinely affected with $\beta$-AA. Thus a deeper understanding of degradation mechanisms promises (A) an insight into defense mechanisms of microorganisms affected with these natural compounds (B) environmental aspects referring to the persistence of $\beta$-AA in soil and water $(C)$ pharmacokinetics of these natural compounds when used as a drug, e.g. cytostatics containing aromatic $\beta$-AA.

The production of chiral $\beta$-AA poses a major challenge in regard to synthetic efficiency and in regard to the used strategy. The solutions include enantioselective synthesis by complex organometallic catalysis, but also by a few enzymatic asymmetric synthesis methods, which must ultimately be more efficient than pure kinetic resolution processes (Juaristi and Soloshonok 2005). Therefore mainly deracemization synthesis strategies were presented on industrial scale as shown by Evonik-Degussa (Grayson et al. 2011). In this strategy, a racemic ester is first produced which is then cleaved in a further reaction by an enantioselective lipase to obtain only one enantiomer as amino acid. The disadvantage is that without racemization (and subsequent dynamic kinetic resolution) the remaining ester enantiomer is usually produced as waste. However, the advantage is that the starting racemate can often be produced in large quantities with little effort, so that chiral resolution turns out to be economically feasible anyway.
Therefore, chiral $\beta$-AA products can be also obtained from enantioselective microbial degradation processes. In case of a deamination to $\beta$-keto acids, the reaction equilibrium is shifted by spontaneous decarboxylation of the products which will be a major subject of this study. For $\beta$-phenylalanine ( $\beta$-PA) as an example for the chiral $\beta$-AA synthesis, a chemical synthesis from benzaldehyde with malonic acid and ammonium acetate to rac- $\beta$-PA would be a starting point for deracemization, as already shown by Grayson et al. (2011). Afterwards, the product could be deracemized by kinetic resolution using an enantioselective transaminase. A fermentation processes might be an alternative to the use of isolated enzymes (Yun et al. 2004; Crismaru et al. 2013; You et al. 2013). In a previous study we performed enrichment cultures from soil samples using aromatic $\beta$-PA as sole nitrogen source (Brucher et al. 2010b). Transamination was found to be the predominant initial degradation step in all isolated bacteria: biotransformation with cell-free extracts and fractions thereof was only observed when a suitable amino acceptor was additionally applied (preferably $\alpha$-ketoglutarate or pyruvate) as well as the well-known transaminase cofactor pyridoxal phosphate (PLP). The fermentative degradation of rac- $\beta$-PA by living cells has only once been documented by Mano et al. in (2006). The $(S)$-selective $\omega$-TA involved in this degradation has been characterized in detail by Hibi et al. (2012). However, the further metabolization of the desaminated $(S)-\beta-\mathrm{PA}$ (and thereby created $\beta$-keto acid, $\beta$-KA) in the degrading microorganism remains as uncertain as the fate of the $(R)-\beta$-AA. Here we report the degradation of racemic $\beta$-PA by the newly isolated Paraburkholderia strain BS115 and the Paraburkholderia type strain P. phytofirmans PsJN. We document the degradation of both enantiomers by the first strain and only one enantiomer by the latter, following product generation and gaining a first insight into the responsible enzymatic mechanisms.

\section{Materials and methods Chemicals}

All amino acids and chemicals were purchased from Sigma Aldrich (St. Louis, US) and Carl Roth (Karlsruhe, Germany) in analytical grade. All enantiopure amino acids were purchased from PepTech Corporation (Bedford, US).

\section{Bacterial strains}

Paraburkholderia BS115 was isolated by enrichment culture from garden soil spiked with soy peptone due to its high content of aromatic amino acids (Brucher et al. 2010b). The strain was identified by the culture collection DSMZ (Deutsche Stammsammlung für Mikroorganismen und Zellkulturen $\mathrm{GmbH}$ ) as P. phytofirmans. 
Cultures of the strain were deposited at the DSMZ designated as DSM 103130 P. phytofirmans (BS115). P. phytofirmans PsJN was also delivered by DSMZ (DSM 17436).

\section{Fermentation process}

The sterile minimal medium $\mathrm{M} 1(\mathrm{pH}$ 7) contained $100 \mathrm{mM}$ D-glucose and $10 \mathrm{mM}$ of rac- $\beta$-PA, $5.8 \mathrm{mM}$ $\mathrm{KH}_{2} \mathrm{PO}_{4}, 4.1 \mathrm{mM} \mathrm{NaHPO}{ }_{4} \cdot 2 \mathrm{H}_{2} \mathrm{O}, 1 \mathrm{mM} \mathrm{MgSO}{ }_{4} \cdot 7$ $\mathrm{H}_{2} \mathrm{O}, 0.5 \mathrm{mM} \mathrm{CaCl} \cdot 2 \mathrm{H}_{2} \mathrm{O}$ and $0.01 \mathrm{mM} \mathrm{FeCl} \cdot 4 \mathrm{H}_{2} \mathrm{O}$. Additionally the vitamins pyridoxal-5-phosphate (PLP) and cobalamin were added to the mixture in concentrations of $1 \mu \mathrm{M}$ and $1 \mathrm{nM}$, respectively. The vitamins, $\beta$-phenylalanine and $\mathrm{FeCl}_{2}$ were sterile filtrated separately while all other compounds were autoclaved. The sterile compounds were then mixed. The fermentation process was optimized for maximal growth rate in a small scale bioreactor system without $\mathrm{pH}$ regulation.

The fermentation of PsJN and BS115 was performed in a benchtop reactor (vessel volume $2.5 \mathrm{~L}$; Minifors, Infors-HT, Switzerland) with a working volume of $1 \mathrm{~L}$ in minimal medium M1. The system was equipped with a $\mathrm{pH}$ probe (Mettler-Toledo, USA) and a Pt-100 temperature probe. The temperature was set to $30^{\circ} \mathrm{C}$ and the stirrer speed was adjusted to $120 \mathrm{rpm}$ at the beginning. For mixing and disruption of gas bubbles a standard Rushton stirrer (diameter $46 \mathrm{~mm}$ ) was used. The $\mathrm{pH}$-value and $\mathrm{pO}_{2}$ content were not controlled, but monitored during the fermentation. The aeration rate was set to $1 \mathrm{~L} / \mathrm{min}$. The experiment was conducted in a triplicate. The precultures were grown in a $100 \mathrm{~mL}$ shake flask in the minimal medium at the same temperature and inoculated from a glycerol stock. The precultures were cultivated in a rotary shaker (Infors-HT, Switzerland) at $120 \mathrm{rpm}$. The bioreactors were inoculated with the precultures to an optical density at $\mathrm{OD}_{600 \mathrm{~nm}}$ of at least 0.1 .

\section{Dry cell mass measurement}

$10 \mathrm{~mL}$ of the cultures were centrifuged at $6000 \mathrm{~g}$ for at least 10 min at $4{ }^{\circ} \mathrm{C}$. The pellets were washed with ${ }_{\mathrm{HP}} \mathrm{H}_{2} \mathrm{O}$ (high-purity water, type I ISO 3696). After this, the cell pellets were dried overnight at $60^{\circ} \mathrm{C}$ in a drying oven.

\section{Glucose assay}

The concentration of D-glucose was measured by an enzymatic glucose-assay from R-Biopharm AG (Darmstadt, Germany). According to the manufacturer's assay protocol volumes were down-scaled to 96-well microtiter plates (scale 1:20). $5 \mu \mathrm{L}$ of the sample was mixed with $100 \mu \mathrm{L}{ }_{\mathrm{HP}} \mathrm{H}_{2} \mathrm{O}$ and $50 \mu \mathrm{L}$ of solution $1.10 \mu \mathrm{L}$ of 1-10 diluted suspension 2 was pipetted to the mixture. The absorption at $340 \mathrm{~nm}$ of the incomplete mixture was measured in an epoch plate reader system before and after suspension 2 was added to the mixture. Also after 5 and $10 \mathrm{~min}$ the absorption was measured. The measurement was calibrated by a D-glucose dilution series from 0.01 to $1 \mathrm{~g} / \mathrm{L}$.

\section{Enzyme activity assay}

Both strains were cultivated for at least 3 days at $120 \mathrm{rpm}$ and $30{ }^{\circ} \mathrm{C}$ in $100 \mathrm{~mL}$ minimal medium in shake flasks, the final $\mathrm{OD}_{600}$ was 3.4 for BS115 and 3.1 for PsJN. The cells were harvested by centrifugation at 8000 rpm in Beckman Coulter (Brea, USA) centrifuge (JA-10 rotor) and lysed by incubation with $1 \mathrm{mg} / \mathrm{mL}$ lysozyme (Fluka) for $15 \mathrm{~min}$ at room temperature. Pellets were resuspended in $5 \mathrm{~mL} 40 \mathrm{mM}$ ice cold sodium phosphate buffer $(\mathrm{pH}$ 7.2) and sonicated for 5 min with $30 \mathrm{~s}$ pulsations at $50 \%$ amplitude. The cell lysate was clarified by centrifugation at $50,000 \mathrm{~g}$ for $30 \mathrm{~min}$ at $4{ }^{\circ} \mathrm{C}$ (Beckman Coulter). The cell free supernatants were used for testing the enzyme activity of both strains: $100 \mu \mathrm{L}$ of lysate were added to $100 \mu \mathrm{L}$ of reaction solution. The consumption rate was normalized by the protein concentration (standard Bradford test) of both lysates (Bradford 1976). The activity test solution contained $15 \mathrm{mM}$ of rac- $\beta$-PA and $15 \mathrm{mM}$ $\alpha$-ketoglutaric acid (amino acceptor). Additionally, $0.1 \mathrm{mM}$ of the cofactor PLP was added to the solution. The solution was buffered by $40 \mathrm{mM}$ sodium phosphate and adjusted at 7.2 with $\mathrm{HCl}$. The reaction temperature was set to $30^{\circ} \mathrm{C}$ and samples were taken at various points. The enzymatic activity was defined as $1 \mathrm{U}=1 \mu \mathrm{mol}$ of converted $\beta$-PA per min. The samples were diluted with preheated sodium phosphate buffer $(40 \mathrm{mM}, 1 \mathrm{mM}$ L-leucin, pH 7.2) and incubated at $99^{\circ} \mathrm{C}$ for $5 \mathrm{~min}$ to stop the reaction. L-leucin was used as internal standard for HPLC analysis.

\section{Quantification of $\beta$-PA by HPLC}

The samples of the fermentation process were centrifuged for at least $5 \mathrm{~min}$ at 13,000 rpm in a bench top centrifuge (Eppendorf, Germany) and used for quantification of $\beta$-PA and AP. The supernatant was used for reversed phase HPLC analysis (Agilent 1200 Serie) by automated precolumn derivatization with ortho-phtaldialdehyde and $N$-isobutyryl-L-cysteine to obtain diasteromers of $\beta$-PA for chiral separation (Brucher et al. 2010a). Therefore, a C18 column $(150 \times 4.6 \mathrm{~mm}$ HyperClone $5 \mu \mathrm{m}$. Phenomenex Inc., Aschaffenburg, Germany) was used. The mobile phase was a mixture of $55 \%$ methanol and $45 \%$ of $40 \mathrm{mM}$ sodium phosphate buffer $(\mathrm{pH}$ 6.5). The flow rate was set to $1 \mathrm{~mL} / \mathrm{min}$ and the column temperature to $40{ }^{\circ} \mathrm{C}$. The diastereomers were monitored by UV-light absorption at $337 \mathrm{~nm}$. The injection volume of the samples for the derivatization mixture was set to $0.5 \mu \mathrm{L}$. The total injection volume of the derivatization mixture was $10 \mu \mathrm{L}$. Calibration was performed using rac- $\beta$-PA $(0-15 \mathrm{mM})$. 
To determine $(R)$ - and $(S)$-enantiomers we used optically pure $\beta$-PA standards from Peptech (Burlington, USA).

\section{Quantification of acetophenone (AP) by HPLC}

No precolumn derivatization was performed to determine acetophenone in samples. Samples were centrifuged for at least $5 \mathrm{~min}$ at $13,000 \mathrm{rpm}$ in a bench top centrifuge. The injection volume of AP was $5 \mu \mathrm{L}$. AP was monitored at $245 \mathrm{~nm}$ using a C18 column (Kinetex $5 \mu \mathrm{m}$ EVO C18 $150 \times 4.6 \mathrm{~mm}$ ). The mobile phase was not changed compared to $\beta$-PA analysis.

\section{Quantification of D-glucose by HPLC}

For quantification of D-glucose in PsJN samples, HPLC was used. This was necessary, because samples showed an interaction with the enzymatic assay. Glucose concentration was measured using an HPLC-system with RI-detector system (Agilent 1100 series). The protocol was adapted from Buchholz et al. (2014). Briefly, samples [S] were precipitated by $4 \mathrm{M} \mathrm{NH}_{3}$ in combination with $1.2 \mathrm{M} \mathrm{MgSO}_{4}$ in volumetric ratio of 0.87 [S]: 0.039 $\left(\mathrm{NH}_{3}\right): 0.087\left(\mathrm{MgSO}_{4}\right)$, incubated for a few minutes at RT and centrifuged at $17,000 \mathrm{~g}$ in benchtop centrifuge. The supernatant was mixed 1:1 (v/v) with $0.1 \mathrm{M} \mathrm{H}_{2} \mathrm{SO}_{4}$ and was again incubated at RT for at least $20 \mathrm{~min}$ and centrifuged at $17,000 \mathrm{~g}$ for $15 \mathrm{~min} .10 \mu \mathrm{L}$ of the supernatant were injected on a Rezex ROA-organic acid $\mathrm{H}^{+}$ column $(300 \times 7.8 \mathrm{~mm}$, Phenomenex). The mobile phase consisted of $5 \mathrm{mM} \mathrm{H}_{2} \mathrm{SO}_{4}$ solution with a flow rate of $0.4 \mathrm{~mL} / \mathrm{min}$. The temperature was set to $50{ }^{\circ} \mathrm{C}$ for the column and $32{ }^{\circ} \mathrm{C}$ for RI-detector. For calculation of the D-glucose concentration, a calibration curve was measured from 0.01 to $0.5 \mathrm{~g} / \mathrm{L}$.

\section{Data analysis}

The maximal growth rate $\mu$ and substrate-consumption were fitted using a sigmoidal equation with three variable parameters to the optical density/dry-cell mass of the cell cultures and to the concentration of $\beta$-PA during the fermentation with data analysis software Sigma Plot (San Jose, USA) adapted to Dörsam et al. (2017). The parameters $\mathrm{a}$ and $\mathrm{b}$ were defined as variables for the sigmoidal equation fit using Sigma Plot. $\mathrm{x}_{0}$ can be interpreted as half maximum of biomass production or as the half amount of the consumed $\beta$-PA and is the inflection point of the function. The variables are $x$ and $f(x)$. The cultivation time was defined as $\mathrm{x}$ in hours. The corresponding $\mathrm{f}(\mathrm{x})$ was defined as optical density, dry cell mass or the concentration of $\beta$-PA $(\mathrm{mM})$.

$$
f(x)=\frac{a}{1+e^{-\frac{x-x_{0}}{b}}}
$$

After fitting of the function against the measured values, the maximal rates were determined by calculating the slope using numeric differentiation with Excel (Microsoft, USA).

\section{Results}

Both strains BS115 and PsJN were able to grow in minimal medium containing $\beta$-PA as sole nitrogen source in $1 \mathrm{~L}$ scale experiments. The fermentation process was started by inoculation of $\beta$-PA induced precultures.

\section{Fermentation of Paraburkholderia}

The main fermentation process of BS115 is illustrated in Fig. 1a. The lag phase of the culture was observed between 0 and $12 \mathrm{~h}$. After this incubation period the culture was growing with maximal growth rate $(12-21 \mathrm{~h})$ until (S)- $\beta$-PA was almost completely consumed. After the preferred enantiomer was depleted, growth continued at a considerably slower rate. The stationary phase was reached $48 \mathrm{~h}$ after inoculation. The total consumed amount of $(R)-\beta$-PA was $2.5 \mathrm{mmol}$ after $50 \mathrm{~h}$ of fermentation. In contrast the AP concentration increased with progressing fermentation and peaked at $4.5 \mathrm{mmol}$, when $(S)-\beta$-PA was almost fully consumed thereby nearly matching the consumed concentration of (S)-PA. Thereafter the AP concentration substantially decreased until the stationary growth phase was reached (Additional file 1: Figure S1).

Growth resulted in a maximal optical density of 7.0, resembling a dry cell mass (DCM) concentration of $1.8 \mathrm{~g} / \mathrm{L}$ at the end of the fermentation. The oxygen concentration before inoculation was set to $100 \%$ and dropped during the process to a minimum of $80 \%$. While centrifuging fermentation samples for analytical purposes, the formation of a slime layer was observed when (S)-B-PA was fully consumed, which reproducibly happened at each fermentation. The extracellular capsule built by BS115 was visualized by negative contrasting with Chinese ink (Additional file 1: Figure S2).

After $24 \mathrm{~h}$ the $\mathrm{pH}$-level dropped from $\mathrm{pH} 7.0$ to $\mathrm{pH}$ 6.0, then remained constant for $20 \mathrm{~h}$, but decreased in the last $10 \mathrm{~h}$ to a final $\mathrm{pH}$ of 3.5 (Additional file 1: Figure S4). The remaining concentration of $\mathrm{D}$-glucose inside the reactor was $27 \pm 1.6 \mathrm{mM}$ and total amount of consumed D-glucose was $73 \mathrm{mM}$. The ratio between consumed carbon to consumed nitrogen $(\mathrm{C}: \mathrm{N})$ was calculated as $14.6 \mathrm{mM}$ per $1 \mathrm{mM}$ of $(S)$ - $\beta$-PA.

We also investigated the fermentation process of PsJN to characterize $\beta$-PA degradation. Furthermore PsJN was used as control strain, to exclude that the degradation of $(R)-\beta-\mathrm{PA}$ is only an unspecific effect during the fermentation process e.g. by adsorption of the amino acid to bacterial cell envelopes or due to other reasons. 


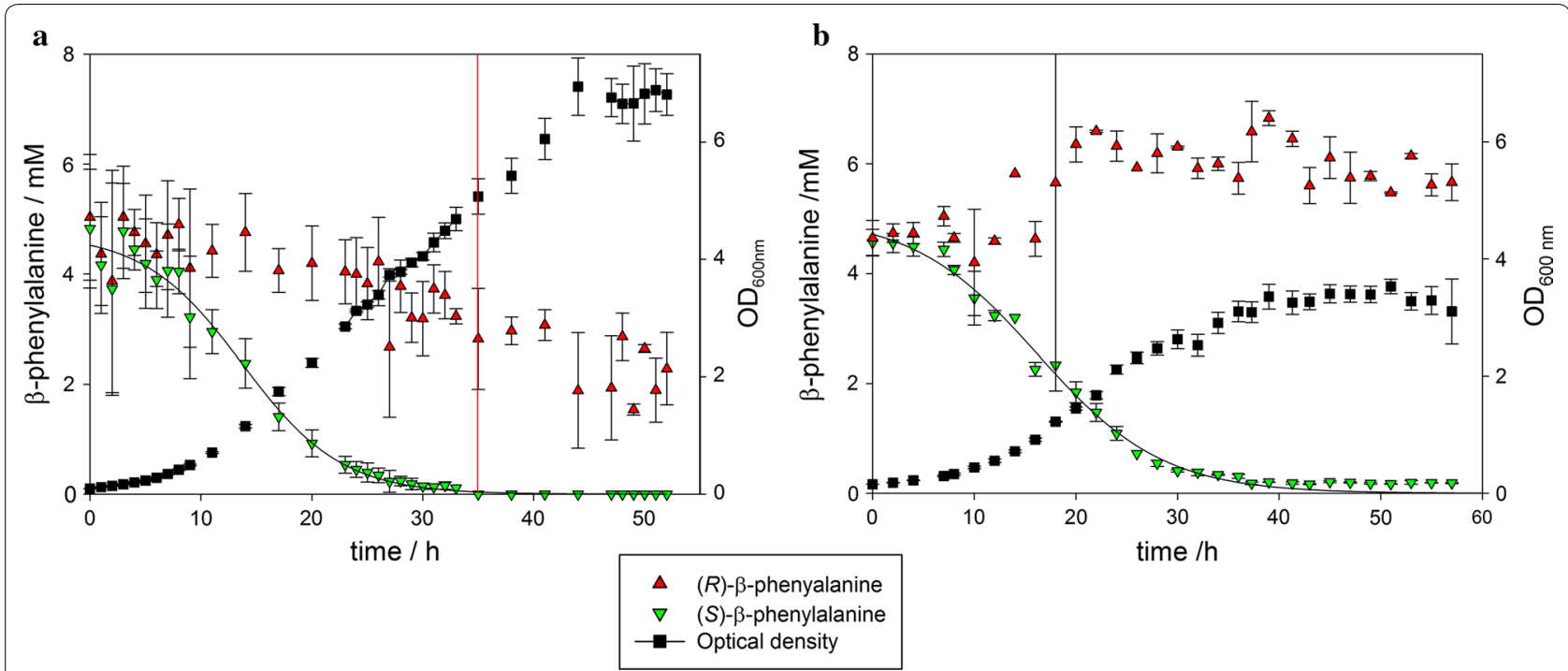

Fig. 1 Degradation of rac- $\beta$-phenylalanine by Paraburkholderia sp. in a $2.5 \mathrm{~L}$ bioreactor. The fermentation was conducted in triplicate at $30^{\circ} \mathrm{C}$ in $1 \mathrm{~L}$ minimal medium M1 with $10 \mathrm{mM}$ of rac- $\beta$-PA. a BS115, b Ps JN. The red line indicates (S)- $\beta$-PA $<1 \%$

The fermentation parameters were maintained according to the BS115 fermentation. The degradation of the $(S)$-enantiomer was almost complete after $38 \mathrm{~h}$, which is in total $5 \mathrm{mM}$ of $\beta$-PA (Fig. 1). During the whole fermentation no degradation of $(R)-\beta-P A$ was observed. The AP concentration increased during the process to a maximum of $1.6 \mathrm{mM}$ after $35 \mathrm{~h}$ (Additional file 1: Figure S1). After $50 \mathrm{~h}$ a slow decrease of the AP concentration in the medium to $0.8 \mathrm{mM}$ was determined. In addition, we also observed only a slight capsulation of the microorganism with increasing fermentation time, which was not observed in shake flask experiments. The total amount of consumed (S)- $\beta$-PA was three times higher than the maximal concentration of $\mathrm{AP}$ in the medium. The $\mathrm{OD}_{600 \mathrm{~nm}}$ reached a maximum of 3.3 which is half the $\mathrm{OD}_{600}$ reached in the BS115 fermentation. The oxygen concentration decreased to a minimum of $70 \%$. In contrast to $\mathrm{BS} 115$, the $\mathrm{pH}$-value dropped from neutral ( $\mathrm{pH} 7$ ) to $\mathrm{pH} 5$, instead of $\mathrm{pH} 3.5$. The $\mathrm{D}$-glucose concentration could not be determined by glucose assay, caused by an inhibition or unknown interaction of the enzymatic assay with the supernatant of the fermentation medium. Therefore, we determined the concentration of $\mathrm{D}$-glucose by HPLC. The remaining concentration of glucose inside the fermentation medium was $21.9 \mathrm{mM} \pm 2.5 \mathrm{mM}$ after $50 \mathrm{~h}$, which is $5 \mathrm{mM}$ less than for BS115. The molar ratio of consumed carbon to nitrogen source was 15.6 per $1 \mathrm{mM}(S)$ - $\beta$-PA. The DCM peaked after $50 \mathrm{~h}$ of cultivation at the concentration of $0.9 \mathrm{~g} / \mathrm{L}$, which is only half as much as for BS115.
Within the 2-day fermentation of BS115, the DCM value of $2 \mathrm{~g} / \mathrm{L}$ is significantly higher than with PsJN, but the $Y_{x / s}$ value of 0.15 is rather low in relation to the amount of biomass produced in relation to the amount of depleted glucose. Surprisingly a consumption of the $(R)$ enantiomer of $\beta$-PA was shown for BS115 but the growth was limited although neither $(R)-\beta$-PA nor glucose was fully depleted. The remaining concentration of glucose was $27 \pm 1.6 \mathrm{mM}$ and the oxygen concentration of $80 \%$ can be ruled out as limiting factor for further growth. The conversion rates of $\beta$-PA and the growth rate $\mu$ and volumetric growth rate $\mathrm{rx}$ were compared in Table 1 . The $\mu_{\max }$ was determined for PsJN after $17.9 \mathrm{~h}$ of cultivation with

Table 1 Characterization of Paraburkholderia sp. fermentation processes

\begin{tabular}{|c|c|c|c|c|c|}
\hline & $\begin{array}{l}\text { Max. } \\
\text { growth } \\
\text { rate } \\
\mu_{\max } \\
(1 / \mathrm{h})\end{array}$ & $\begin{array}{l}\text { Max. } \\
\text { volumetric } \\
\text { growth } \\
\text { rate } r x[g / \\
(\mathrm{L} \mathrm{h})]\end{array}$ & $\begin{array}{l}\text { Max. }(S)-\beta-P A \\
\text { volumetric } \\
\text { consumption } \\
\text { rate } Q_{(s)-P A} \\
(\mathrm{mM} / \mathrm{h})\end{array}$ & $\begin{array}{l}\text { Max. specific } \\
(S)-\beta-P A \\
\text { consumption } \\
\text { rate } q_{(S)-P A} \\
{[\mathrm{mmol} /(\mathrm{g} \mathrm{h})]}\end{array}$ & $t_{d}(h)$ \\
\hline $\begin{array}{l}\text { Parabur- } \\
\text { kholde- } \\
\text { ria } \\
\text { phyto- } \\
\text { firmans } \\
\text { PSJN }\end{array}$ & 0.14 & 0.036 & 0.21 & -2.1 & 4.95 \\
\hline $\begin{array}{c}\text { Parabur- } \\
\text { kholde- } \\
\text { ria sp. } \\
\text { BS115 }\end{array}$ & 0.23 & 0.063 & 0.26 & -1.3 & 3.0 \\
\hline
\end{tabular}

The calculations are based on the mean values of three independent fermentations 
$0.14 \mathrm{~h}^{-1}$, which is equate to a doubling time $\left(\mathrm{t}_{\mathrm{d}}\right)$ of $4.95 \mathrm{~h}$. In contrast, the strain BS115 reached a $\mu_{\max }$ of $0.23 \mathrm{~h}^{-1}$ after $27.0 \mathrm{~h}$ of cultivation.

During fermentation BS115 grew 1.6 times faster than PsJN on $\beta$-PA (Fig. 2). The $\mathrm{Q}_{(s) \text {-PA }}$ rate was calculated to be $0.26 \mathrm{mM} / \mathrm{h}$ for BS115 after $14.2 \mathrm{~h}$ (Fig. 3). The $\mathrm{Q}_{(s) \text {-PA }}$ rate of PsJN was slightly lower with $0.21 \mathrm{mM} / \mathrm{h}$ after $16.2 \mathrm{~h}$ of cultivation time. In addition the $\mathrm{q}_{(s)-\mathrm{PA}}$ was determined for both strains, which is correlated to the biomass concentration. On the other hand BS115 had a specific $\mathrm{q}_{(s)-\mathrm{PA}}$ rate which is slightly lower with $0.74 \mathrm{mmol} / \mathrm{g} / \mathrm{h}$ compared to PsJN with $0.88 \mathrm{mmol} / \mathrm{g} / \mathrm{h}$ (Fig. 3).

PsJN produced less biomass but the cells converted $(S)$ $\beta$-PA more efficiently. PsJN started to convert with maximal specific consumption rate, whereas BS115 reached its maximal consumption rate after $8 \mathrm{~h}$ of cultivation time. In contrast to $(S)-\beta-\mathrm{PA}$, the consumption rate of $(R)$ - $\beta$-PA could not be fitted for BS115, caused by the high variances and inconstant decreasing rate between 25 and $50 \mathrm{~h}$ of cultivation. The volumetric production rate $\mathrm{Q}_{\mathrm{AP}}$ of $\mathrm{AP}$ reached a maximum of $0.07 \mathrm{mM} / \mathrm{h}$ for PsJN after $10.8 \mathrm{~h}$ of fermentation. After several hours the AP concentration decreased with a much slower with a $\mathrm{Q}_{\mathrm{AP}}$ rate of $0.01 \mathrm{mM} / \mathrm{h}$. Initially, the $\mathrm{BS} 115 \mathrm{Q}_{\mathrm{AP}}$ rate was faster than calculated for PsJN, with $0.34 \mathrm{mM} / \mathrm{h}$.

\section{$\boldsymbol{\omega}$-Transaminase activity test}

The $\beta$-PA degrading activity of both strains were tested with cell free lysate from BS115 and compared to PsJN lysate. The temperature was set to $30{ }^{\circ} \mathrm{C}$ according to the cultivation temperature of BS115 and PsJN. For the transamination reaction $0.1 \mathrm{mM}$ of the $\omega$-TA cofactor molecule PLP and selected $\alpha$-ketoglutarate as acceptor
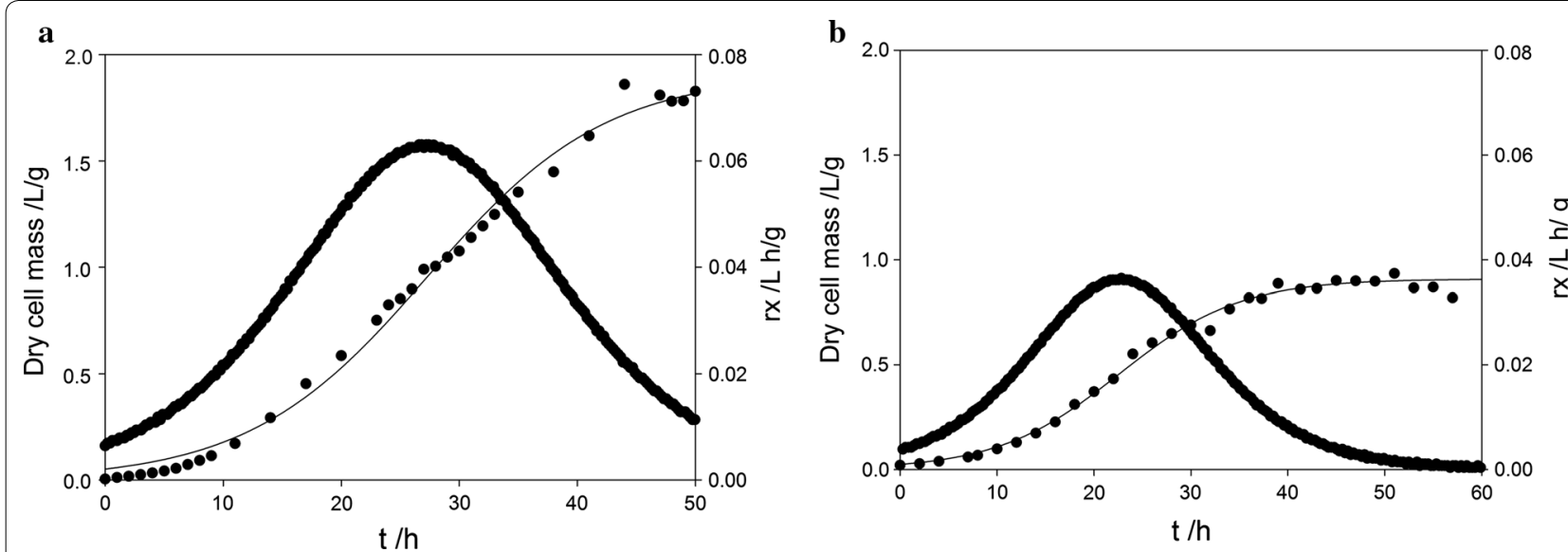

Fig. 2 Dry cell mass building rate of $\mathbf{a}$ BS115 and $\mathbf{b}$ PsJN. The dry cell mass data points were fitted with a three parameter sigmoid function with an $R^{2}$ of 0.99 . This function was used to calculate the slope $(\triangle D C M / \triangle t)$
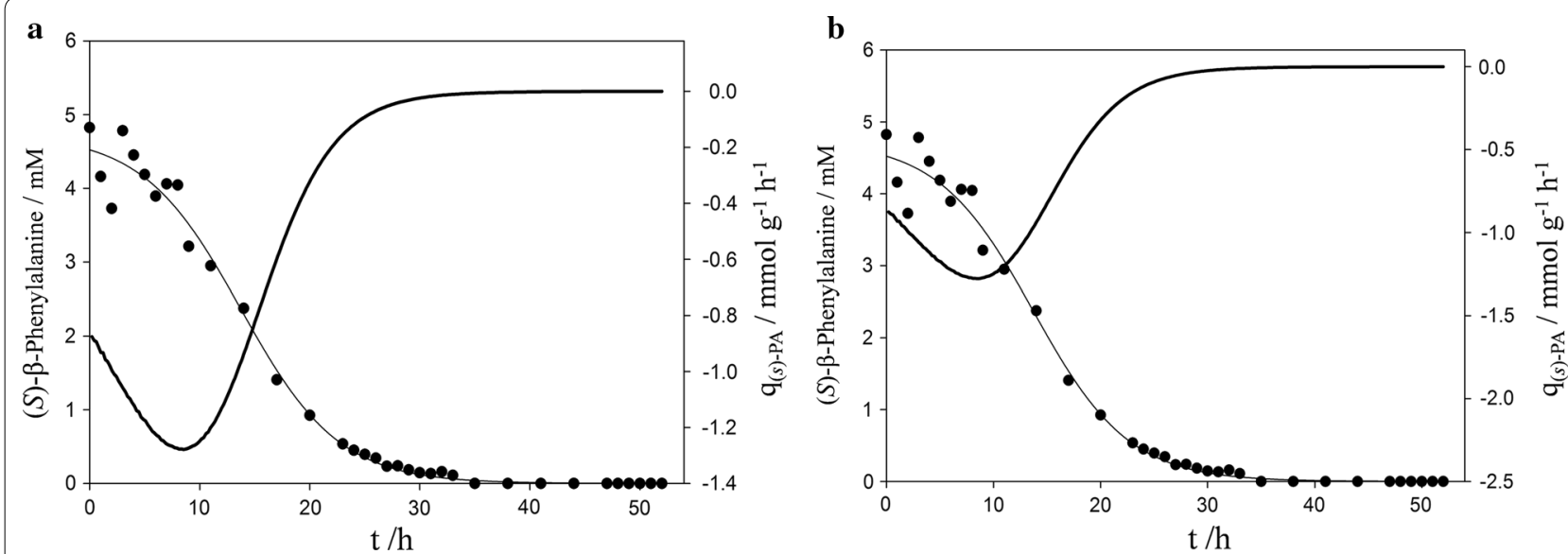

Fig. 3 Consumption rate of (S)- $\beta$-PA. Bold line $-q_{(S)-P A}$. Points with line-concentration of (S)- $\beta$-PA in bioreactor. a BS115, b PSJN 
molecule was added due to the compatibility towards well characterized $\beta$-phenylalanine transaminases (Wybenga et al. 2012; Crismaru et al. 2013). The final concentration of applied protein in the reaction mixture was $0.47 \mathrm{mg} / \mathrm{mL}$ for PsJN and $0.95 \mathrm{mg} / \mathrm{mL}$ for BS115. The concentration of rac- $\beta$-PA in the lysate-reaction mixture was determined at different times, to recognize slow and fast conversions as well as long-term effects (Additional file 1: Figure S3). After $24 \mathrm{~h}$ both lysates showed only activity for $(S)-\beta$-PA and a complete conversion of the (S)-enantiomer. The transaminase activity at the beginning of the reaction was considerably higher for PsJN lysate than for BS115. The specific activities of both preparations were calculated between samples of $15 \mathrm{~s}$ and $1 \mathrm{~h}$ and varied between $35 \pm 5 \mathrm{mU} / \mathrm{mg}$ for PsJN and $8 \pm 4 \mathrm{mU} / \mathrm{mg}$ for BS115. In total, the amounts of the obtained lysate activity was $1.25 \mathrm{U}$ and $0.32 \mathrm{U}$ in $100 \mathrm{~mL}$ cell culture at an $\mathrm{OD}_{600}$ of 3.1 .

\section{Characterization of BS115 $\omega$-TA}

The $\omega$-TA activity of BS115 was characterized. The activity of the putative enzyme was higher in a slightly alkaline TRIS-buffer system at $\mathrm{pH}$ 8. In addition to $\alpha$-ketoglutarate the BS115 lysate also showed activity towards the amino acceptors pyruvate and oxaloacetate. However, for the latter acceptor molecules the activity was $50 \%$ lower compared to $\alpha$-ketoglutarate. Moreover, derivatives of $\beta$-PA were tested as amino donors. The transaminase activity was higher towards non-substituted $\beta$-PA and in contrast relatively low for $\beta$-PA with a chlorine in para position at the phenyl-ring. Also remarkable is that the enantioselectivity decreased only for the strong polar nitro-substituent (Table 2).

By contrast, the putative $\omega$-TA from BS115 showed no activity towards rac- $\beta$-homophenylalanine, which comprises only one additional carbon atom between the amino group and phenyl ring. In the case of variation of the substituents of the phenyl-ring of $\beta$-PA, the enzymes showed a wide promiscuity.

\section{Discussion}

\section{Degradation of (S)- $\beta$-PA by BS1 15 and PsJN}

Both Paraburkholderia strains BS115 and PsJN were able to grow with $(S)-\beta$-PA as sole source of nitrogen. The metabolization of the $\mathrm{N}$-source most likely occurs via a transaminase reaction in which the amino group of $(S)-\beta-\mathrm{PA}$ is transferred to an $\alpha$-keto acid. Although $\alpha$-ketoglutarate has been shown to be the most suitable in vitro amino acceptor, the in vivo application of other molecules like pyruvate is also possible.

Deracemization of $\beta$-PA by living cells has only once been reported so far: The only comparable fermentation example from Mano et al. showed that the soil bacterium Variovorax sp. JH2 is able to convert (S)-selective $61 \mathrm{mM}$
Table 2 Substrate spectrum of putative BS115 $\omega$-TA

\begin{tabular}{lll}
\hline Amino-donor & $\begin{array}{l}\text { Relative } \\
\text { activity } \\
\text { (\%) }\end{array}$ & ee \\
\hline $\begin{array}{l}\text { rac-3-amino-3-phenylpropionic acid ( } \beta \text {-PA) } \\
\text { rac-3-amino-4-phenylbutyric acid }\end{array}$ & 100 & $>99 \%$ \\
$\quad(\beta-h o m o p h e n y l a l a n i n e)$ & 0 & - \\
$\begin{array}{l}\text { rac-3-amino-3-(4-methoxyphenyl)propionic acid } \\
\text { (S)-3-amino-3-(4-hydroxyphenyl)propionic acid }\end{array}$ & 46 & $>96 \%$ \\
$\quad(\beta-t y r o s i n e)$ & 69 & - \\
rac-3-amino-3-(4-fluorophenyl)propionic acid & 61 & $>99 \%$ \\
rac-3-amino-3-(4-nitrophenyl)propionic acid & 34 & $>91 \%$ \\
rac-3-amino-3-(4-chlorophenyl)propionic acid & 19 & $>99 \%$ \\
\hline
\end{tabular}

The reactions were carried out in $50 \mathrm{mM}$ TRIS-buffer at $\mathrm{pH}$ 8, with an acceptor molecule concentration of $5 \mathrm{mM}$. The total protein-concentration of the cell lysate was set to $0.2 \mathrm{mg} / \mathrm{mL}$. ee\% was determined after $30 \mathrm{~min}$ of reaction time

of $\beta$-PA within 8 days (Mano et al. 2006). They achieved a maximal degradation rate of $0.26 \mathrm{mM} / \mathrm{h}$ towards $(S)$ $\beta$-PA, which is comparable to the uptake rates of PsJN and BS115. The approach to utilize living cells for chiral resolution of $\mathrm{rac}-\beta$-PA should be tested in further experiments at larger scales and at higher concentration levels, to prove whether a microbial process might be able to compete with established industrial deracemization processes using lipases demonstrated by former EvonikDegussa company (Grayson et al. 2011). Yeast cells have successfully been used for the chiral resolution of alcohols and more recent examples document the microbial resolution e.g. of DL-glyceric acid (Glänzer et al. 1987; Kometani et al. 1995; Sato et al. 2015).

The rapid degradation of the $(S)$-enantiomer, in contrast to the $(R)$-enantiomer, resulted in a reduction of the $\mathrm{pH}$-value by metabolizing almost half of the $\mathrm{D}$-glucose. According to this, the final $\mathrm{pH}$ value of 3.5 is most likely to be limiting. In addition it could be seen that during BS115 fermentation the $\mathrm{pH}$-value stagnated at a constant value of 5 for several hours before it dropped to 3.5. A total consumption of the $(R)$-enantiomer might be possible, if the fermentation process was $\mathrm{pH}$ regulated. The fermentation parameters quantified are valuable for using the strains as microbial target to investigate metabolic pathways of the rac- $\beta$-PA metabolization to ultimately achieve the microbial synthesis of $\beta-\mathrm{PA}$, as has already been established for $\alpha$-amino acids (Sanchez et al. 2017). In contrast the experiments lead to the assumption, that BS115 is able to convert ( $R$ )- $\beta$-PA by a so far unknown mechanism (Fig. 4). The lowering of the $\mathrm{pH}$ value indicates that either an organic acid is formed or a previously buffering substance [e.g. $\beta$-PA (pI 5.84)] has been consumed by BS115. $\beta$-PA could thus itself act as a buffer at $\mathrm{pH} 5.8$, but continuing degradation leads to further acidification due to the resulting $\beta$-keto acid production. 


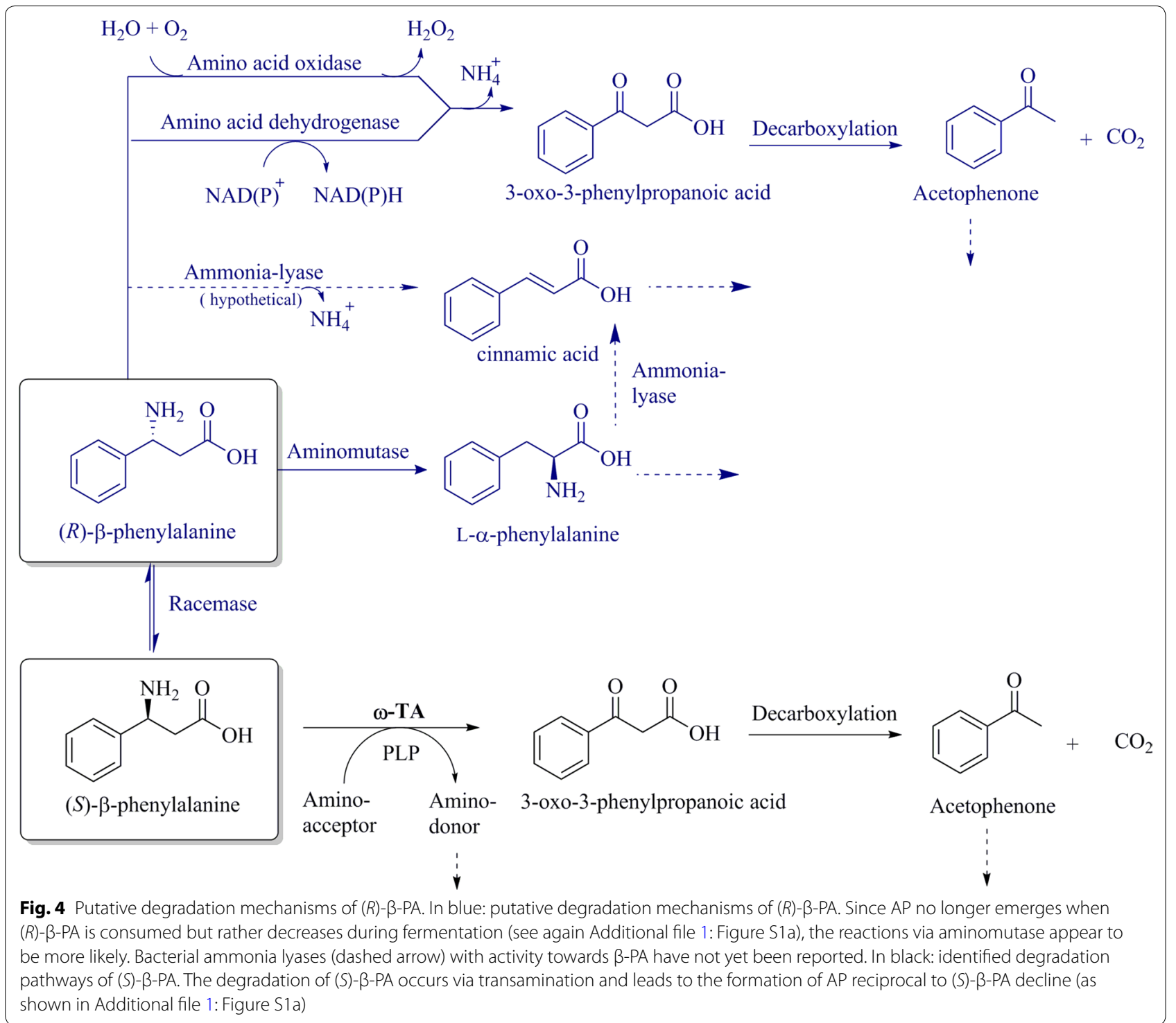

\section{By-product analysis}

The proposed transamination of $(S)-\beta$-PA leads to the corresponding $\beta$-keto acid 3-oxo-3-phenylpropanoic acid. However, this molecule has never been detected in medium as it spontaneously decarboxylates to AP as has been shown in previous studies (Crismaru et al. 2013; Dold et al. 2016). AP on the other hand was shown to emerge in parallel to the degradation of $(S)$ - $\beta$-PA, peaking for both strains after about $30 \mathrm{~h}$ when $(S)-\beta-\mathrm{PA}$ is depleted (Additional file 1: Figure S1). Progress of AP formation rate and $(S)-\beta$-PA degradation rate are nearly identical for both strains which is strong evidence for the proposed transamination mechanism (Fig. 4). In BS115, even the molar concentrations of emerging AP and metabolized (S)- $\beta$-PA are close to identical. So it is most likely that after transamination the corresponding $\beta$-keto acid decarboxylates and the emerging AP is excreted.

After depletion of (S)- $\beta$-PA, AP concentration in the medium notably decreases. Substantial evaporation of the volatile AP can be excluded from control experiments (data not shown). A reuptake of AP is possible, but from the data at hand it cannot be stated whether AP serves as additional carbon source or as amino acceptor without further metabolization which would also lead to the observed depletion. Rehdorf et al. showed in Pseudomonas putida strain JD1, that a Baeyer-Villiger monooxygenase converts 4-hydroxy AP to phenylacetate. Finally, phenyl-acetate is further degraded via a $\beta$-ketoadipate metabolic pathway. At the same time, the enzyme is also able to convert AP (Rehdorf et al. 2009). 
This metabolic pathway releases acetic acid, which should lower the $\mathrm{pH}$ value of the fermentation medium. This is supported by the fact that at the very time when acetophenone decreases drastically (after $40 \mathrm{~h}$ ), also the $\mathrm{pH}$ value of BS115 fermentation decreases from 6 to 4 (Additional file 1: Figure S4).

Further experiments with a different Paraburkholderia strain demonstrated that AP can be reduced by a carbonyl reductase (Singh et al. 2009), which might serve as an evidence for further metabolization inside the cells. It is also known that Burkholderia sp. expresses a reductase which is able to reduce 2-aminoacetophenone to 2-amino-1-phenylethanol (Yamada-Onodera et al. 2007). The same reductase might also be able to convert AP. Furthermore PsJN is known to degrade even more complex aromatic biomolecules like the plant hormone indole-3-acetic acid by a rather complex degradation pathway to catechol (Donoso et al. 2017). So a bacterial metabolization of AP as a reason for its decrease is most likely.

\section{Superior growth of BS115}

Although both strains clearly metabolize (S)- $\beta$-PA via the same mechanism, BS115 reaches a final $\mathrm{OD}_{600}$ twice as high as that of PsJN under identical growth conditions. According to 16S-rDNA sequencing, both strains show $>99 \%$ identity, so the basic metabolism might not differ too much and maybe only one additional enzyme makes up the severe difference in growth. However, it is also possible that different enzymes from other microbial sources are integrated in BS115 genome via horizontal gene transfer, especially when the strain was exposed to extraordinary amino sources in soil. Since the PsJN cultures obviously reach the stationary phase when $(S)-\beta-\mathrm{PA}$ is depleted although sufficient amounts of $D$-glucose are still at hand, a growth stop can be explained by the inability of this strain to use the $(R)$-enantiomer as nitrogen source; $(R)-\beta$-PA remains completely unconsumed during the whole fermentation. A growth inhibition by other factors like toxic metabolites is unlikely since the closely related strain BS115 very probably faces similar but even stronger stress conditions (e.g. ongoing acidification, depletion of other nutrients than N-source).

Moreover, BS115 shows a quite similar cell dry mass per depleted ( $S$ )- $\beta$-PA minus depleted ( $R$ )- $\beta$-PA. In total BS115 built $1.82 \mathrm{~g}$ of biomass per liter and consumed $7.72 \mathrm{mM}$ of rac- $\beta$-PA, that is a ratio of $4.3 \mathrm{~g} /$ $(\mathrm{mM}(\beta-\mathrm{PA}))$. In contrast PsJN built only $0.82 \mathrm{~g} / \mathrm{L}$ (ratio $5.9 \mathrm{~g} /(\mathrm{mM}(\beta-\mathrm{PA}))$ and was at the same time more efficient in using only $(S)$-PA. So we postulate at least one additional enzyme in BS115 which allows the metabolization or $(R)-\beta$-PA as additional $\mathrm{N}$-source and potentially also as additional $\mathrm{C}$-source, leading to a better growth and to the formation of considerably more cell dry mass from the same medium.

\section{Degradation of $(R)-\beta-P A$ by BS115}

Several options of amino acid metabolization are identified and well investigated (see also "Introduction" section), and most of these also seem conceivable for the degradation of $(R)-\beta$-PA. Since activity has only been observed in growing cells, a cofactor-dependent mechanism is likely. Moreover, an additional transaminase would have been detected under the given conditions, and also a side activity of the identified (S)- $\beta$-PA can be excluded: $(R)$ and $(S)$ - $\omega$-TAs show only low sequence identities and can clearly be differentiated by protein fold types (Höhne et al. 2010; Buß et al. 2018a). A transamination of $(R)-\beta-\mathrm{PA}$ would have led to the formation of AP, but on the contrary the concentration of AP decreased. Several $(R)$-selective $\omega$-TAs have been described for the ability to convert and synthesize $(R)$-configurated amines. However, activity towards aromatic or bulky $\beta$-AAs were only observed for $(S)$-selective $\omega$-TAs (Koszelewski et al. 2010; Seo et al. 2012; Dold et al. 2016) and no (R)-PA converting transaminase has been reported until now (Mutti et al. 2011; Mallin et al. 2014; Jiang et al. 2015; Skalden et al. 2015). Only Mano et al. investigated an $(R)$ selective strain, Arthrobacter sp. AKU 638, which is suitable for chiral resolution to gain the optical pure $(S)-\beta$-PA. However, this degradation process is very slow and took 13 days of fermentation and in contrast to BS115 they did not recognize any depletion of the $(S)$-enantiomer at the same time (Mano et al. 2006). Oxidative deamination has been suggested, but until now, the mechanism for the degradation of (R)- $\beta$-PA in Arthrobacter sp. AKU 638 is uncovered. Only recently it was also shown that the ethyl ester of $(R)$-PA can be converted by a commercial fold type IV transaminase (ATA117 11Rd), which however has been largely modified and no longer shows a high identity to wild-type $\omega$-TA (Buß et al. 2018b). Therefore, it seems unlikely that such a transaminase can occur in BS115, especially since tests with cell lysate do not indicate any transaminase reaction.

In fact, the metabolism of (R)- $\beta$-PA has only been reported for microorganism with assured aminomutases or ammonia lyases genes (Szymanski et al. 2009; Jiang et al. 2015; Weise et al. 2015). The activity of aminomutases is described as quite low which might explain the rather slow degradation of (R)- $\beta$-PA using BS115 (Bartsch et al. 2013). Also several amino acid oxidases exist with high activity towards several amines (Alexeeva et al. 2002; Ghislieri et al. 2013), but as yet amino acid oxidases with activity towards $\beta$-PA have not been published. Analogously no wildtype $\beta$-amino acid dehydrogenase is known; the only example of a dehydrogenase 
with activity towards $\beta$-PA is an engineered enzyme from the amino acid fermenting bacterium Candidatus cloacamonas (Zhang et al. 2015).

However, PA-racemases have been described for the racemization between $\mathrm{L}$ and $\mathrm{D}-\alpha-\mathrm{PA}$ in bacteria (Conti et al. 1997) and for plants the Taxus (yew) PA aminomutase is known to use $\alpha$-phenylalanine as substrate to produce $(R)-\beta$-PA (Cox et al. 2009). In contrast, no bacterial $\beta$-phenylalanine lyase was reported so far, so it is rather unlikely that $\beta-\mathrm{PA}$ is degraded by a lyase; however, this possibility is shown in Fig. 4 for completeness. Wu et al. showed that a PA mutase from Taxus chinensis can be utilized for chiral separation of rac- $\beta$-PA. The corresponding $\alpha-\mathrm{PA}$ is then degraded to cinnamic acid using an $\alpha$-PA ammonia lyase from Rhodosporidium toruloides. The reported reaction time for chiral resolution was quite long with more than $48 \mathrm{~h}$ using $2 \mathrm{mM}$ of substrate (Wu et al. 2010). Apart from this also $\beta$-tyrosine aminomutase is known from Oryzae sativa with high enantioselectivity towards (R)- $\beta$-PA (Walter et al. 2016). So a slow enzymatic racemization of $(R)$-PA to $(S)$-PA and further metabolization of the latter by BS115 appears at least possible; but no bacterial aminomutase with such an activity is known until now.

\section{Hypothetical degradation pathway for (R)- $\beta$-PA}

Recently Csuka et al. (2017) reported that Pseudomonas fluorescens R124 encodes three different class I lyase like enzymes, namely an ammonia-lyase, an aromatic 2,3 aminomutase and a histidine ammonia-lyase. The authors describe, that under nitrogen limitation, $P$. fluorescens is able to integrate new genes by horizontal gene transfer to overcome limitations. Therefore BS115 might be adapted towards special nitrogen limitations, even when the genome is quite similar to PsJN. For this reason it might be possible that BS115, in the presence of $(S)$ $\beta$-PA, expresses an ammonia-lyase or 2,3 aminomutase which could convert $(R)-\beta-\mathrm{PA}$ to cinnamic acid. The transmutation of an ammonia-lyase into a 2,3 aminomutase is possible by a single mutation and can change the functionality of a mutase to a lyase (Bartsch et al. 2013). The vice versa functionality change of a lyase to a mutase has not yet been reported, but attempts have been made to determine the decisive amino acid residues using mutation studies of e.g. Attanayake et al. (2018). Bacterial aminomutase with $\beta$-PA activity would also be rather unexpected, although not unthinkable, considering that horizontal gene shifts are possible. In this case, any cinnamic acid produced could be largely metabolized. This pathway has been shown in Pseudomonas strains where cinnamic acid is metabolized to $o$-hydroxyphenylpropionic acid and to 2,3-dihydroxyphenylpropionic acid (Blakley and Simpson 1964). BS115 might be able to regenerate $\mathrm{NAD}(\mathrm{P})^{+}$by this way using an NADP oxidoreductase. In high concentrations cinnamic can also be reduced by NADH using fumarate reductase or by an oxygen-sensitive 2-enoate reductase (Hillier et al. 1979; Sun et al. 2016). An oxygen-sensitive enzyme would also give an explanation why the activity is hard to detect in crude extracts without further protective measures.

This assumption is supported by growth experiments on enantiopure $(R)$ and $(S)-\beta$-PA as nitrogen sources, as BS115 is only able to degrade $(R)-\beta$-PA in the presence of (S)- $\beta$-PA and not when added as sole N-source (Fig. 5). The experiments showed that $(S)-\beta$-PA was completely converted, whereas the $(R)$-enantiomer as sole nitrogen source remained untouched even after a cultivation duration of $70 \mathrm{~h}$ (Fig. 5a). On the other hand, the $(R)$-enantiomer was substantially degraded in the presence of (S)- $\beta$-PA (Fig. $5 \mathrm{~b}$ ). Only $40 \%$ of $10 \mathrm{mM}(R)$-enantiomer retained within the cultivation medium after $70 \mathrm{~h}$. Since growth continues after complete depletion of $(S)-\beta-\mathrm{PA}$, $(R)-\beta$-PA is obviously made accessible as nitrogen source by one of the mechanisms depicted in Additional file 1: Figure S4. Moreover $(R)-\beta$-PA might also serve as additional carbon source or as electron acceptor if cinnamic acid is produced.

All of the above discussed potential pathways and metabolization steps using the addressed different enzymes are also summarized in Fig. 4. These results also confirm the report from Mano et al., that no activity can be detected in cell-free lysate of an Arthrobacter sp. AKU 638 strain for $(R)-\beta$-PA consumption. Furthermore, the reported very slow degradation, might hint to a similar mechanism using the same enzyme as in BS115.

We characterized the degradation of racemic $\beta$-PA by a 3 days fermentation of two Paraburkholderia strains PsJN and BS115 in a $2.5 \mathrm{~L}$-benchtop fermenter in $1 \mathrm{~L}$ medium. PsJN exhibited strict $(S)$-selectivity and therefore can be utilized as whole cell biocatalyst to obtain $(R)-\beta$-PA in high optical purity by chiral resolution. The spontaneous decarboxylation of the emerging $\beta$-keto acid to acetophenone, for the first time documented over the whole degradation process, shifts the equilibrium irreversibly towards the desired direction. However, as a process with industrial relevance a high cell density fermentation has to be developed with medium conditions allowing much higher substrate concentrations, which is currently limited by the low water solubility of $\beta$-PA. Therefore an alternative would be to perform a fed batch fermentation. After uncovering the degradation pathway of $(S)$ - and (R)- $\beta$-PA in Paraburkholderia sp., these strains might be optimized for the production of $\beta$-PA as has already been shown for several $\alpha$-amino acid production strains (Sanchez et al. 2017). The abilities to synthesize $(R)$-configurated aromatic amines and amino acids 

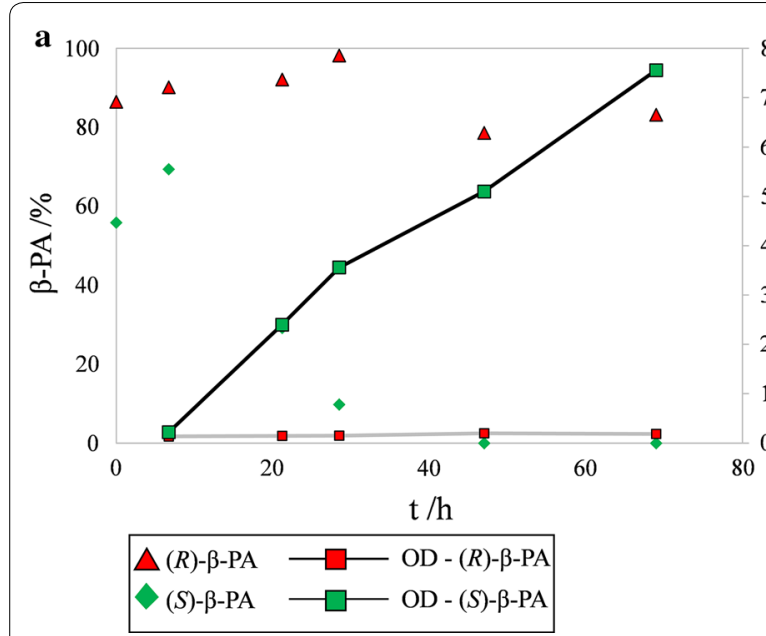

$30^{\circ} \mathrm{C}$
$120 \mathrm{rpm}$
$25 \mathrm{~mL}$

b

b 100
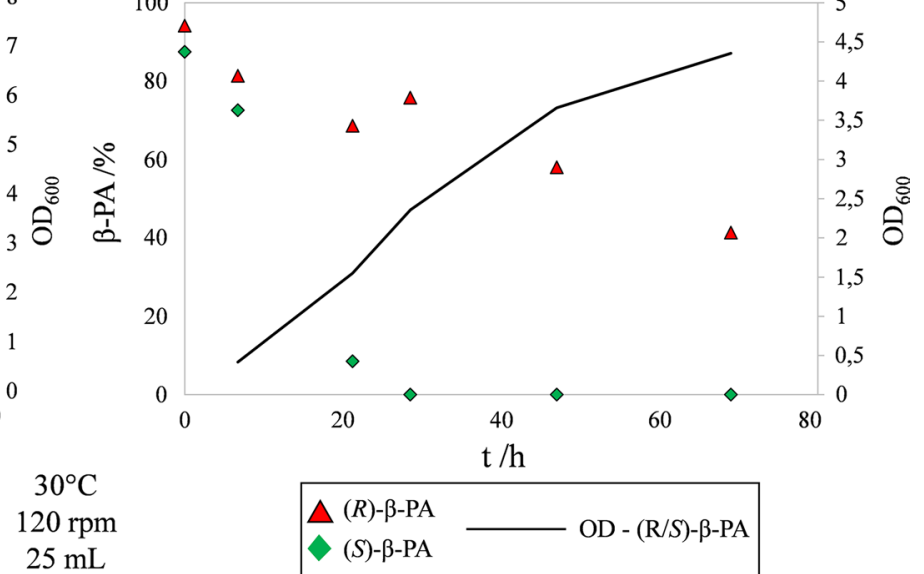

Fig. 5 Conversion of $(R)-\beta-P A$ in presence of the $(S)$-enantiomer (b) and no conversion as sole nitrogen source (a). The experiment was performed using optically pure $\beta$-PA in minimal medium. BS115 was pre-cultivated on (R/S)- $\beta$-PA for 3 days in shaking-flaks

by asymmetric synthesis are limited by the availability of $(R)$-selective enzymes; so far, only few plant enzymes are known for the synthesis of $(R)$ - $\beta$-PA (Ratnayake et al. 2016; Buß et al. 2018b). So the investigation of the $(R)$ $\beta$-PA degradation process in BS115 might not only lead to a deeper understanding of the biochemical pathways of $\beta$-AA but to novel approaches for the chemoenzymatic synthesis of this highly relevant substance class.

\section{Additional file}

Additional file 1: Figure S1. Acetophenone (AP) content during fermentation process in comparison to (S)- $\beta$-PA concentration. AP concentration rises inversely proportional to (S)- $\beta$-PA degradation and decreases after (S)- $\beta$-PA depletion. a) BS115 fermentation b) PSJN fermentation. Figure S2. Extracellular capsule built by BS115 during fermentation after depletion of (S)- $\beta$-PA. The capsule of BS115 was visualized by negative contrasting with Chinese ink. Figure S3. Transaminase activity of cell free lysate of BS115 and PSJN. In red triangles: ( $R$ )- $\beta-P A$; in green triangles (S)- $\beta$-PA. The reaction was performed at $30^{\circ} \mathrm{C}$ in reaction mixture (see also section 2.6 ) of 12 $\mathrm{mM}$ of rac- $\beta$-PA using a-ketoglutarate as amino acceptor. The reaction and sampling time was chosen to depict fast reactions as well as possible long-term effects. Figure S4. pH profile during fermentation of BS115 and PSJN in $1.5 \mathrm{~L}$ bioreactor systems using minimal medium. In contrast to PSJN, BS1 15 showed a stabilization of the pH value between 20 and 40 h. Figure S5. Chiral separation of $\beta$-PA using IBLC-OPA pre-column derivatization and reversed phase HPLC according to Brucher et al. (2010a). The retention time of the $(R)$-enantiomer is $3.7 \mathrm{~min}$, of the (S)-enantiomer $4.8 \mathrm{~min}$. Figure S6. Relative transaminase activity of BS115 in regard to $\mathrm{pH}$. The reactions were performed with $2.5 \mathrm{mM}$ of racemic $\beta$-phenylalanine using $0.5 \mathrm{mg} / \mathrm{mL}$ of protein at $30^{\circ} \mathrm{C}$.

\section{Abbreviations}

$\beta$-AA: $\beta$-amino acid; $\beta$-PA: $\beta$-phenylalanine; AP: acetophenone; Q-AP: volumetric production rate $A P ; Q_{(s)-P A}$ : volumetric consumption rate $(S)-\beta-P A ; q_{(s)-P A}$ : specific consumption rate; $\mu_{\max }$ : max. growth rate; $\mathrm{t}_{\mathrm{d}}$ : doubling time; $Y_{\mathrm{x} / \mathrm{s}}$ : biomass yield per substrate amount; $r_{x}$ : volumetric growth rate.

\section{Authors' contributions}

OB: Performance of the experiments, HPLC analysis, data evaluation and advisory of the lab work. Writing the manuscript as first author. SD: Substantial performance of the experiments with Paraburkholderia BS115 and HPLC analysis. JG: Substantial supporting of the experiments with Paraburkholderia PSJN. PO: Performance of the fermentation with Paraburkholderia. DM: Performance of precultures and supporting by preparation of medium. DL: Performance of cell-free activity tests. JR: Isolation of BS115, performance of microscopy and staining, substantial contribution to the conception of manuscript and of the experiments as well as advisory of the lab work. Critically revising of the final manuscript version. All authors read and approved the final manuscript.

\section{Acknowledgements}

The authors acknowledge the Federal Ministry of Science and Education (BMBF), Germany for funding this project as part of the joint project Molecular Interaction Engineering (MIE, funding code 031A095B). We also thank Prof. Dr. Syldatk for supporting our work and Jennifer Kirchhoff, Michaela Zwick for their dedicated support. Dr. Ulrike Engel and Dr. Katrin Ochsenreither carefully proofread the revised manuscript. Finally, we acknowledge support by Deutsche Forschungsgemeinschaft and Open Access Publishing Fund of Karlsruhe Institute of Technology.

\section{Competing interests}

The authors declare that the research was conducted in the absence of any commercial or financial relationships that could be construed as a potential competing interests.

\section{Consent for publication}

Not applicable.

\section{Dedication}

This publication is dedicated in memoriam Prof. Hans G. Trüper (1936-2016) who originally named the bacterial species investigated in this study and inspired one of the authors as scientific teacher and mentor.

\section{Ethics approval and consent to participate} Not applicable.

\section{Funding}

Federal Ministry of Science and Education (BMBF)—Molecular Interaction Engineering (MIE)_Funding code 031A095B. 


\section{Publisher's Note}

Springer Nature remains neutral with regard to jurisdictional claims in published maps and institutional affiliations.

Received: 27 March 2018 Accepted: 6 September 2018

Published online: 21 September 2018

\section{References}

Alexeeva M, Enright A, Dawson MJ, Mahmoudian M, Turner NJ (2002) Deracemization of a-methylbenzylamine using an enzyme obtained by in vitro evolution. Angew Chem Int Ed 41:3177-3180. https://doi. org/10.1002/1521-3773(20020902)41:17

Attanayake G, Walter T, Walker KD (2018) Understanding which residues of the active site and loop structure of a tyrosine aminomutase define its mutase and lyase activities. Biochemistry 57:3503-3514. https://doi. org/10.1021/acs.biochem.8b00269

Bartsch S, Wybenga GG, Jansen M, Heberling MM, Wu B, Dijkstra BW, Janssen DB (2013) Redesign of a phenylalanine aminomutase into a phenylalanine ammonia lyase. ChemCatChem 5:1797-1802. https://doi. org/10.1002/cctc.201200871

Blakley ER, Simpson FJ (1964) The microbial metabolism of cinnamic acid. Can J Microbiol 10:175-186. https://doi.org/10.1139/m64-025

Bradford MM (1976) A rapid and sensitive method for the quantitation of microgram quantities of protein utilizing the principle of protein-dye binding. Anal Biochem 72:248-254. https://doi.org/10.1016/00032697(76)90527-3

Brucher B, Rudat J, Syldatk C, Vielhauer O (2010a) Enantioseparation of aromatic $\beta^{3}$-amino acid by precolumn derivatization with $o$-phthaldialdehyde and $N$-isobutyryl-L-cysteine. Chromatographia 71:1063-1067. https ://doi.org/10.1365/s10337-010-1578-x

Brucher B, Syldatk C, Rudat J (2010b) Mikrobielle Umsetzung von $\beta$-Phenylalanin mittels neuer Transaminasen. Chemie Ing Tech 82:155160. https://doi.org/10.1002/cite.200900110

Brückner H, Hausch M (1989) Gas chromatographic detection of D-amino acids as common constituents of fermented foods. Chromatographia 28:487-492. https://doi.org/10.1007/BF02261066

Buß O, Buchholz PCF, Gräff M, Klausmann P, Rudat J, Pleiss J (2018a) The $\omega$-transaminase engineering database (OTAED): a navigation tool in protein sequence and structure space. Proteins Struct Funct Bioinform. https ://doi.org/10.1002/prot.25477

Buß O, Voss M, Delavault A, Gorenflo P, Syldatk C, Bornscheuer U, Rudat J (2018b) $\beta$-phenylalanine ester synthesis from stable $\beta$-keto ester substrate using engineered $\omega$-transaminases. Molecules 23:1211. https://doi. org/10.3390/molecules23051211

Buchholz J, Graf M, Blombach B, Takors R (2014) Improving the carbon balance of fermentations by total carbon analyses. Biochem Eng J 90:162-169. https://doi.org/10.1016/j.bej.2014.06.007

Conti E, Stachelhaus T, Marahiel MA, Brick P (1997) Structural basis for the activation of phenylalanine in the non-ribosomal biosynthesis of gramicidin S. EMBO J 16:4174-4183. https://doi.org/10.1093/emboj/16.14.4174

Cox BM, Bilsborrow JB, Walker KD (2009) Enhanced conversion of racemic a-arylalanines to $(R)$ - $\beta$-arylalanines by coupled racemase/aminomutase catalysis. J Org Chem 74:6953-6959. https://doi.org/10.1021/jo9009563

Crismaru CG, Wybenga GG, Szymanski W, Wijma HJ, Wu B, Bartsch S, de Wildeman S, Poelarends GJ, Feringa BL, Dijkstra BW, Janssen DB (2013) Biochemical properties and crystal structure of a $\beta$-phenylalanine aminotransferase from Variovorax paradoxus. Appl Environ Microbio 79:185-195. https://doi.org/10.1128/AEM.02525-12

Csuka P, Juhász V, Kohári S, Filip A, Varga A, Sátorhelyi P, Bencze LC, Barton HA, Paizs C, Poppe $L$ (2017) Pseudomonas fluorescens strain R124 encodes three different MIO-enzymes. ChemBioChem 19:411-418. https://doi. org/10.1002/cbic.201700530

Dold S-M, Cai L, Rudat J (2016) One-step purification and immobilization of a $\beta$-amino acid aminotransferase using magnetic (M-PVA) beads. Eng Life Sci 16:568-576. https://doi.org/10.1002/elsc.201600042

Donoso R, Leiva-Novoa P, Zúñiga A, Timmermann T, Recabarren-Gajardo G, González B (2017) Biochemical and genetic bases of indole-3-acetic acid (auxin phytohormone) degradation by the plant-growth-promoting rhizobacterium Paraburkholderia phytofirmans PsJN. Appl Environ Microbiol 83:e01991-16. https://doi.org/10.1128/AEM.01991-16

Dörsam S, Fesseler J, Gorte O, Hahn T, Zibek S, Syldatk C, Ochsenreither K (2017) Sustainable carbon sources for microbial organic acid production with filamentous fungi. Biotechnol Biofuels 10:242. https://doi. org/10.1186/s13068-017-0930-x

Drozak J, Veiga-da-Cunha M, Vertommen D, Stroobant V, Van Schaftingen E (2010) Molecular identification of carnosine synthase as ATP-grasp domain-containing protein 1 (ATPGD1). J Biol Chem 285:9346-9356. https://doi.org/10.1074/jbc.M109.095505

Duan X, Li Y, Du Q, Huang Q, Guo S, Xu M, Lin Y, Liu Z, Xie J (2016) Mycobacterium Lysine $\varepsilon$-aminotransferase is a novel alarmone metabolism related persister gene via dysregulating the intracellular amino acid level. Sci Rep 6:19695. https://doi.org/10.1038/srep19695

Ghislieri D, Green AP, Pontini M, Willies SC, Rowles I, Frank A, Grogan G, Turner NJ (2013) Engineering an enantioselective amine oxidase for the synthesis of pharmaceutical building blocks and alkaloid natural products. J Am Chem Soc 135:10863-10869. https://doi.org/10.1021/ja4051235

Glänzer Bl, Faber K, Griengl H (1987) Enantioselective hydrolyses by baker's yeast-III: microbial resolution of alkynyl esters using lyophilized yeast. Tetrahedron 43:5791-5796. https://doi.org/10.1016/S0040-4020(01)87785-1

Grayson Jl, Roos J, Osswald S (2011) Development of a commercial process for (S)- $\beta$-phenylalanine. Org Process Res Dev 15:1201-1206. https://doi. org/10.1021/op200084g

Hibi M, Mano J, Hagishita T, Shima J, Shimizu S, Ogawa J (2012) $\beta$-Aryl- $\beta$-amino acid aminotransferase from Variovorax sp. JH2 is useful for enantioselective $\beta$-phenylalanine production. Biocatal Agric Biotechnol 1:253-258. https://doi.org/10.1016/J.BCAB.2012.04.001

Hillier AJ, Jericho RE, Green SM, Jago GR (1979) Properties and function of fumarate reductase (NADH) in Streptococcus Lactis. Aust J Biol Sci 32:625-636. https://doi.org/10.1071/B19790625

Höhne M, Schätzle S, Jochens H, Robins K, Bornscheuer UT (2010) Rational assignment of key motifs for function guides in silico enzyme identification. Nat Chem Biol 6:807-813. https://doi.org/10.1038/nchembio.447

Jiang J, Chen X, Zhang D, Wu Q, Zhu D (2015) Characterization of (R)-selective amine transaminases identified by in silico motif sequence blast. Appl Microbiol Biotechnol 99:2613-2621. https://doi.org/10.1007/s0025 3-014-6056-1

Juaristi E, Soloshonok VA (2005) Enantioselective synthesis of $\beta$-amino acids. Wiley, Hoboken

Kanehisa M, Sato Y, Kawashima M, Furumichi M, Tanabe M (2016) KEGG as a reference resource for gene and protein annotation. Nucleic Acids Res 44:D457-D462. https://doi.org/10.1093/nar/gkv1070

Kometani T, Morita Y, Yoshii H, Kiyama Y, Matsuno R (1995) Oxidative resolution with bakers'yeast for large-scale of chiral 1,2-alkanediols production. J Ferment Bioeng 80:180-184

Koszelewski D, Tauber K, Faber K, Kroutil W (2010) $\omega$-Transaminases for the synthesis of non-racemic a-chiral primary amines. Trends Biotechnol 28:324-332. https://doi.org/10.1016/j.tibtech.2010.03.003

Kudo F, Miyanaga A, Eguchi T, Huang SX, Unsin C, Tao M, Coughlin JM, Shen B, Salas JA, Ullrich C, Stein T, Leenders F, Vater J, Poelarends GJ (2014) Biosynthesis of natural products containing $\beta$-amino acids. Nat Prod Rep 31:1056 https://doi.org/10.1039/C4NP00007B

Magriotis PA (2001) Recent progress in the enantioselective synthesis of B-lactams: development of the first catalytic approaches. Angew Chem Int Ed 40:4377. https://doi.org/10.1002/1521-3773(20011 203)40:23\%3c4377:AID-ANIE4377\%3e3.0.CO;2-J

Mallin H, Höhne M, Bornscheuer UT (2014) Immobilization of (R)- and (S)amine transaminases on chitosan support and their application for amine synthesis using isopropylamine as donor. J Biotechnol 191:32-37. https:// doi.org/10.1016/j.jbiotec.2014.05.015

Mano J, Ogawa J, Shimizu S (2006) Microbial production of optically active $\beta$-phenylalanine through stereoselective degradation of racemic B-phenylalanine. Biosci Biotechnol Biochem 70:1941-1946. https://doi. org/10.1271/bbb.60099

Mutti FG, Fuchs CS, Pressnitz D, Sattler JH, Kroutil W (2011) Stereoselectivity of four $(R)$-selective transaminases for the asymmetric amination of ketones. Adv Synth Catal 353:3227-3233. https://doi.org/10.1002/adsc.201100558

Nutzenadel W, Scriver CR (1976) Uptake and metabolism of $\beta$-alanine and L-carnosine by rat tissues invitro: role in nutrition. Am J Physiol 230:643-651 
Radkov AD, Moe LA (2014) Bacterial synthesis of d-amino acids. Appl Microbiol Biotechnol 98:5363-5374. https://doi.org/10.1007/s00253-014-5726-3

Ratnayake ND, Theisen C, Walter T, Walker KD (2016) Whole-cell biocatalytic production of variously substituted $\beta$-aryl-and $\beta$-heteroaryl- $\beta$ amino acids. J Biotechnol 217:12-21. https://doi.org/10.1016/j.jbiot ec.2015.10.012

Rehdorf J, Zimmer CL, Bornscheuer UT (2009) Cloning, expression, characterization, and biocatalytic investigation of the 4-hydroxyacetophenone monooxygenase from Pseudomonas putida JD1. Appl Environ Microbiol 75:3106-3114. https://doi.org/10.1128/AEM.02707-08

Sanchez S, Rodríguez-Sanoja R, Ramos A, Demain AL (2017) Our microbes not only produce antibiotics, they also overproduce amino acids. J Antibiot (Tokyo). https://doi.org/10.1038/ja.2017.142

Sato S, Morita T, Fukuoka T, Kitamoto D, Habe H (2015) Microbial resolution of DL-glyceric acid for L-glyceric acid production with newly isolated bacterial strains. J Biosci Bioeng 119:554-557. https://doi.org/10.1016/J.JBIOS C.2014.10.016

Seebach D, Gardiner J (2008) $\beta$-Peptidic peptidomimetics. Acc Chem Res 41:1366-1375. https://doi.org/10.1021/ar700263g

Seo Y-M, Mathew S, Bea H-S, Khang Y-H, Lee S-H, Kim B-G, Yun H (2012) Deracemization of unnatural amino acid: homoalanine using D-amino acid oxidase and $\omega$-transaminase. Org Biomol Chem 10:2482. https://doi. org/10.1039/c2ob07161d

Singh A, Basit A, Banerjee UC (2009) Burkholderia cenocepacia: a new biocatalyst for efficient bioreduction of ezetimibe intermediate. J Ind Microbiol Biotechnol 36:1369-1374. https://doi.org/10.1007/s10295-009-0622-z

Skalden L, Thomsen M, Höhne M, Bornscheuer UT, Hinrichs W (2015) Structural and biochemical characterization of the dual substrate recognition of the $(R)$-selective amine transaminase from Aspergillus fumigatus. FEBS J 282:407-415. https://doi.org/10.1111/febs.13149

Spitzer ED, Jimenez-Billini HE, Weiss B (1988) $\beta$-Alanine auxotrophy associated with dfp, a locus affecting DNA synthesis in Escherichia coli. J Bacteriol 170:872-876. https://doi.org/10.1128/JB.170.2.872-876.1988

Steer DL, Lew RA, Perlmutter P, Smith Al, Aguilar M-I (2002) $\beta$-amino acids: versatile peptidomimetics. Curr Med Chem 9:811-822. https://doi. org/10.2174/0929867024606759

Sun J, Lin Y, Shen X, Jain R, Sun X, Yuan Q, Yan Y (2016) Aerobic biosynthesis of hydrocinnamic acids in Escherichia coli with a strictly oxygen-sensitive enoate reductase. Metab Eng 35:75-82. https://doi.org/10.1016/j.ymben .2016 .02 .002

Szymanski W, Wu B, Weiner B, De Wildeman S, Feringa BL, Janssen DB (2009) Phenylalanine aminomutase-catalyzed addition of ammonia to substituted cinnamic acids: a route to enantiopure $\alpha$ - and $\beta$-amino acids. J Org Chem 74:9152-9157. https://doi.org/10.1021/jo901833y
Tao F, Zhou Z, Zhang T, Xu H, Yang J, Ding W, Guo Y (2017) Method for preparation of tobacco flavor with honey and aromatic $\beta$-amino acid. CN 2016-10793745. Available at https://patents.google.com/patent/CN106 244322A/en

Voet D, Voet JG (2011) Biochemistry. Wiley, New York

Walter T, King Z, Walker KD (2016) A tyrosine aminomutase from rice (Oryza sativa) isomerizes ( $S$ )- $\alpha$ - to $(R)$ - $\beta$-tyrosine with unique high enantioselectivity and retention of configuration. Biochemistry 55:1-4. https://doi. org/10.1021/acs.biochem.5b01331

Wani MC, Taylor HL, Wall ME, Coggon P, McPhail AT (1971) Plant antitumor agents. VI. The isolation and structure of taxol, a novel antileukemic and antitumor agent from Taxus brevifolia. J Am Chem Soc 93:2325-2327

Weise NJ, Parmeggiani F, Ahmed ST, Turner NJ (2015) The bacterial ammonia lyase EncP: a tunable biocatalyst for the synthesis of unnatural amino acids. J Am Chem Soc 137:12977-12983. https://doi.org/10.1021/ jacs. 5 b07326

Wu B, Szymański W, de Wildeman S, Poelarends GJ, Feringa BL, Janssen DB (2010) Efficient tandem biocatalytic process for the kinetic resolution of aromatic $\beta$-amino acids. Adv Synth Catal 352:1409-1412. https://doi. org/10.1002/adsc.201000035

Wybenga GG, Crismaru CG, Janssen DB, Dijkstra BW (2012) Structural determinants of the $\beta$-selectivity of a bacterial aminotransferase. J Biol Chem 287:28495-28502. https://doi.org/10.1074/jbc.M112.375238

Yamada-Onodera K, Takase Y, Tani Y (2007) Purification and characterization of 2-aminoacetophenone reductase of newly isolated Burkholderia sp. YT. J Biosci Bioeng 104:416-419. https://doi.org/10.1263/jbb.104.416

You P, Qiu J, Su E, Wei D (2013) Carica papaya lipase catalysed resolution of $\beta$-amino esters for the highly enantioselective synthesis of (S)-dapoxetine. Eur J Org Chem 2013:557-565. https://doi.org/10.1002/ejoc.20120 1055

Yun H, Lim S, Cho B, Kim B (2004) w-Amino acid: pyruvate transaminase from Alcaligenes denitrificans $Y 2 k-2$ : a new catalyst for kinetic resolution of $\beta$ -amino acids and amines-amino acid: pyruvate transaminase from Alcaligenes denitrificans Y2k-2: a new catalyst for kinetic resolut. Appl Environ Microbiol 70:2529-2534. https://doi.org/10.1128/AEM.70.4.2529

Zhang D, Chen X, Zhang R, Yao P, Wu Q, Zhu D (2015) Development of $\beta$-amino acid dehydrogenase for the synthesis of $\beta$-amino acids via reductive amination of $\beta$-keto acids. ACS Catal 5:2220-2224. https://doi. org/10.1021/cs5017358

Ziegelbauer K, Babczinski P, Schönfeld W (1998) Molecular mode of action of the antifungal beta-amino acid BAY 10-8888. Antimicrob Agents Chemother 42:2197-2205

\section{Submit your manuscript to a SpringerOpen ${ }^{\circ}$ journal and benefit from:}

- Convenient online submission

- Rigorous peer review

- Open access: articles freely available online

- High visibility within the field

Retaining the copyright to your article

Submit your next manuscript at springeropen.com 